\title{
Evaluation of the Potential of Trichogramma chilonis Ishii (Hymenoptera: Trichogrammatidae) as a Bio-control Agent for Trichoplusia ni, Cabbage Semi-looper
}

\author{
S.A.A. Singhamuni, M.I.U.F. Jayasuriya ${ }^{1}$, K.S. Hemachandra ${ }^{1 *}$ \\ and U.G.A.I. Sirisena ${ }^{2}$ \\ Postgraduate Institute of Agriculture \\ University of Peradeniya \\ Sri Lanka
}

\begin{abstract}
Trichogrammachilonis is a potential biological control agent of Trichoplusiani. Whenever the activity of bio-control agents is not sufficient, insecticide applications also may necessary to avoid economic crop loss. Therefore, the performance of $\underline{T}$. chilonis was evaluated under the exposure of insecticides belong to different categories. It was found that profenophos was highly lethal to adult (74\% mortality) and neem (7\%) and chlorofluazuron (5.2\%) were relatively safer for them. The survived adults showed significant variations on their longevity and capacity of parasitisation. Average longevities of the survived adults after exposed to the same insecticides were 1.3, 7.0 and 5.2 days, and their levels of parasitism were 8.3, 48.0 and 51.5\%, respectively. Similarly, it was also found that profenophos was highly lethal for immature stage (100\% mortality) compared tochlorofluazuron and neem, which showed only $17.6 \%$ and $22.7 \%$ mortality, respectively. Parasitoids that emerged withstanding exposure to chlorofluazuron and neem showed the average longevity of 6.2 and 7.6 days respectively, and their percentage of parasitism were 64.6 and 61.6, respectively across all immature stages of the host. The residue effect of profenophos and chlorofluazuron was significant up to 10 days and the ecosystem was safer for parasitoids after 15 days. Studies also indicated that host-plant volatiles have less involvement in searching behaviour of T. chilonis. Therefore, it is capable of locating the host using host volatile and can be easily mass reared using alternative host eggs. Further, $\underline{T}$. chilonis search eggs across the cabbage leaves, leaving no refuge eggs. The rate of parasitism positively responded to host egg density and it parasitized all possible eggs within five hours if the eggs are in ample supply. Due to this efficient searching and parasitisation ability, survival and performance under insecticide exposure, $\underline{T}$. chilonis can

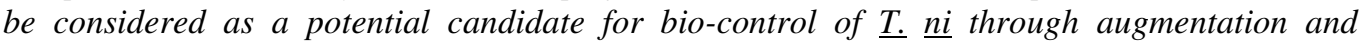
release.
\end{abstract}

Keywords: Dispersal, longevity, mortality, parasitism, Trichogramma

\section{INTRODUCTION}

Crucifer vegetables, i.e. cabbage, radish, knol-khol are popular vegetable crops in Sri Lanka and its annual extent of cultivation is around of 8,300 ha (DOA, 2013). Management of cabbage

\footnotetext{
1 Department of Agricultural Biology, Faculty of Agriculture,University of, Peradeniya, Sri Lanka.

2 Department of Plant Sciences, Faculty of Agriculture, Rajarata University of Sri Lanka

* Corresponding author: kshema@pdn.ac.lk
} 
caterpillar complex is the major challenge faced by the growers. Cabbage caterpillar complex includes diamondback moth (Plutella xylostella), cabbage semi-looper (Trichoplusia ni), Crosidolomia pavonana, and cabbage heart caterpillar (Hellula undalis). At present, growers heavily depend on application of insecticides in controlling this pest complex. The Department of Agriculture of Sri Lanka, has recommended chlorfluazuron 5\% EC, quinalphos 25\% EC and profenophos 50\% EC to control the caterpillar pest complex (DOA, 2010).

Frequent application of insecticides is common among the commercial growers. Excessive use of agro-chemicals leads to many ecological and health problems, which have been well documented. Among the ecological problems, development of resistance in insect populations, pest resurgence, secondary pest outbreaks, soil and water contamination and effects on nontarget organisms, especially the parasitoids and predators can be highlighted (Ooi and Shepard, 1994; Heong et al., 1995). Insecticide application is associated with a risk of acute and chronic exposure of spray operators, farmers and consumers (Sheiner, et al., 2003; Bassil et al., 2007; Jurewicz and Hanke, 2008; Gilden et al., 2010). Consequently, the personal and national health bill associated with the use of pesticides is quite substantial. One of the alternative options available for controlling the pest complex is biological control using egg parasitoids. Use of larval and pupal parasitoids has limitations and has practical problems such as pest larvae die at the later instars or at pupal stage by the action of larval or pupal parasitoids resulting continuous crop damage As a result, the level of control by the action of parasitoids is not adequate to minimize the foliage damage. However, egg parasitoids have been successfully used in many similar situations in other countries. Therefore, the potential use of egg parasitoids to manage the cabbage caterpillar complex under the presence of insecticide application was suggested in this research programme.

The risk involved in biological control is rather minimal, when locally available parasitoid species are used, when compared with the exotic parasitoids. Hence, a survey was conducted to identify the locally available egg parasitoids, subsequently, two species of egg parasitoids, Trichogramma achaeae, and Trichogramma chilonis were identified (Hemachandra et al., 2013). However, if the egg parasitoids are to be used in biological control, it is necessary to evaluate their searching ability and their tolerant level to insecticide exposure. Therefore, the objectives of this study were to assess the ability of $T$. chilonis searching host eggs, and the level of tolerance of $T$. chilonis for insecticide spray / residues to understand the potential use of $T$. chilonis as a bio-control agent of Trichoplusia ni in cabbage ecosystem.

\section{METHODOLOGY}

This study was conducted based in the Department of Agricultural Biology, Faculty of Agriculture, University of Peradeniya, during 2012-2013. Egg parasitoid, T. chilonis was reared on Corcyra cephalonica eggs to get adults for experimentation. C. cephalonica was reared on crushed corn as described by TNAU AGRITECH PORTAL (2012).

\section{Effect of insecticides on mortality and behaviour of Trichogramma chilonis}

\section{Effect of insecticides on mortality, longevity and parasitizing capacity of adult Trichogramma chilonis}

Mortality, longevity and parasitizing capacity of adult parasitoids were examined after exposing them to different insecticides prepared as per label information. Filter papers $\left(4 \mathrm{~cm}^{2}\right)$ were submerged in (a) neem, (neemzal, $2 \mathrm{ml} / \mathrm{L}$ ) (b) chlorfluazuron 50g/L EC (1 ml/L), (c) 
profenophos $500 \mathrm{~g} / \mathrm{L} \mathrm{EC}(2 \mathrm{ml} / \mathrm{L})$ and water as a control for 10 minutes and allowed the papers to air dry. These dilutions were used in all experiments in this study. The papers containing different insecticides were inserted into clear plastic vials when the adults were in the vials. Each vial contained 50 one day old adults. Mortality, longevity and parasitizing capacity of adult were examined with 20 replicates of each treatment $(50$ x 20 adults per treatment). Methodology of this experiment was adapted from Sattar et al. (2011).

\section{Effect of insecticides on mortality of immature stages of Trichogramma chilonis}

Three different embryonic stages of T. chilonis: egg, larva and pupa (1, 5 and 7 day old after parasitisation) were exposed to different insecticides and the mortality was recorded. The insecticides used in the experiment include: (a) neem (b) chlorfluazuron $50 \mathrm{~g} / \mathrm{L}$ EC (c) profenophos $500 \mathrm{~g} / \mathrm{L} \mathrm{EC}$ and (d) water as the control. Parasitized egg cards which contain 50 eggs were submerged in different insecticide solutions for 1 minute and air dried. The treated egg cards were incubated until the emergence of adult parasitoids. Level of parasitoid emergence was recorded for each treatment. After emergence, randomly selected two parasitoid females from each vial were exposed to egg card which contain 100 eggs to examine the level of parasitism. The longevity of the adult parasitoid was also observed with 10 replicates of each treatment with bee honey as a food source. Methodology for this experiment was adapted from Rahman and Aziz (2012).

\section{Effect of insecticide residues on substrate on acceptance of host eggs by adult Trichogramma chilonis}

Cabbage plants, required for the experiment were prepared as potted plants following the recommended agronomic practices. Potted cabbage plants were sprayed as per the label recommendation with (a) neem (b) chlorfluazuron $50 \mathrm{~g} / \mathrm{L} \mathrm{EC}$, (c) profenophos $500 \mathrm{~g} / \mathrm{L} \mathrm{EC}$, and (d) water as the control using a hand sprayer. Treated plants were maintained in open field conditions, to facilitate the natural degradation of insecticide. After a definite period of time, small pieces of cabbage leaves $(2 \times 2 \mathrm{~cm})$ were separated from each treated plant and 50 eggs of C. cephalonica were glued on to the leaf piece. The leaf piece with eggs was placed in clear plastic vials and two parasitoid females of $T$. chilonis were introduced into the vial allowing them to parasitize the eggs. Leaf samples from treated cabbage plants were obtained in different time intervals: One hour, 5 days, 15 days and 25 days and subject to above procedure to examine the acceptance of eggs by parasitoids. The level of parasitism of eggs was assessed by counting the parasitized eggs under the microscope (10 x 7). Methodology of this experiment was adapted from Sattar et al. (2011).

Host searching behaviour of Trichogramma Chilonis: Influence of host, host density, and the substrate on host finding behavior of Trichogramma chilonis

Efficacy of parasitoids which is reflected by biological and behavioural characteristics is highly influential on success of biological programmes; therefore, the behaviour of T. chilonis was examined in these experiments.

\section{Effect of host substrate for host finding behaviour}

It is believed that the parasitoids obtained cues from the host plant in search of host for parasitization which has an effect on time taken for host search. In this experiment, the time taken by adult female parasitoid to find the host eggs was measured. Clear plastic vials $(2.5 \mathrm{~cm}$ diameter and $6.7 \mathrm{~cm}$ height) were used as the experimental arena. The C. cephalonica eggs were 
prepared for the experiment by making egg cards; freshly laid eggs were glued on a $1 \times 1 \mathrm{~cm}$ filter paper. After preparing all required materials and ready for observation, newly emerged $T$. chilonis female parasitoid was placed on the bottom of the clear plastic vial. Previously prepared egg card was also placed inside the vial near the rim of the vial and closed the vial with the lid. From this point, the time taken to find the $C$. cephalonica egg by the female parasitoid was measured using a stop watch while continuously observing the experimental arena. Same experimental procedure was repeated by changing the substrate. Instead of filter paper, $1 \mathrm{x} 1 \mathrm{~cm}$ cabbage leaf or $1 \times 1 \mathrm{~cm}$ croton (non host plant) leaf was used to prepare the egg card. Observations were taken and the experiment was replicated 20 times for each substrate with newly emerged $T$. chilonis adults.

\section{Effect of host density on host finding behaviour}

Number of $C$. cephalonica eggs glued to the substrate was changed as 3, 5, 7 and the same experimental procedure was followed. Secondly, Trichoplusia ni eggs were used instead of $C$. cephalonica eggs. The experiment was replicated 20 times with twenty different T. chilonis mated females.

\section{Searching behaviour of Trichogramma chilonis within cabbage plant}

In this experiment, ability of $T$. chilonis searching eggs within cabbage plant was examined. Successful search of host eggs was confirmed by examining the parasitism of host eggs. Three layers of leaves (lower, middle, upper) of a potted cabbage plant were used as search arena. In each layer, one leaf was selected and within the leaf, five places on upper surface and five places on lower surface of that leaf were selected to place the host eggs (Figure 1). On each point, an egg card (1 x $1 \mathrm{~cm}$ filter paper) with five eggs was placed.

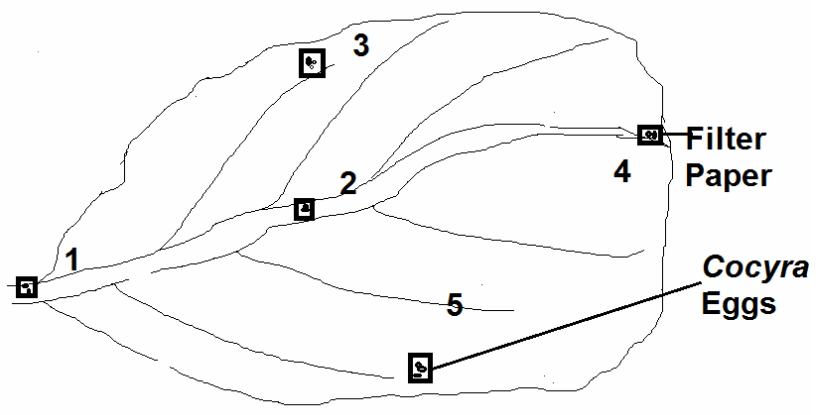

Fig. 1. Selected five points of the cabbage leaf

The prepared cabbage plant was kept in the insect cage and 15 female parasitoids were released into the cage. Plant and the parasitoids were maintained in the cage for three days. On the fourth day, plant was taken out and each egg card was separated and placed in a clear plastic vial. The vials were labelled and eggs were incubated within the vial. Six days later, eggs were examined for parasitism as the parasitized eggs turn black. The experiment was repeated with ten plants, and considered as ten replicates.

\section{Time taken for maximum parasitism with adlibitum access to host eggs}

This experiment was conducted from 8.00 am to $5.00 \mathrm{pm}$. Egg card with 20 C. cephalonica eggs was introduced to a female parasitoid within a clear plastic vial. After one hour, egg card was 
replaced with fresh egg card with 20 C. cephalonica eggs. In every hour, up to nine hours egg cards were replaced. The removed egg cards were incubated for five days and the number of parasitized eggs turned black was counted. Fifteen replicates were used in this experiment.

\section{Relationship between parasitism level and host density}

Adult female parasitoid was introduced into a clear plastic vial $(2.5 \mathrm{~cm}$ diameter and $6.7 \mathrm{~cm}$ height) with a host egg card containing either 15, 25, 75 or 100 eggs. After 24 hours, female parasitoid was removed and eggs were incubated for five days and the number of parasitized eggs was counted. Fifteen replicates were used in this experiment.

\section{RESULTS AND DISCUSSION}

\section{Effect of insecticides on mortality and behaviour of Trichogramma chilonis}

\section{Effect of insecticides on mortality, longevity and parasitizing capacity of adult Trichogramma chilonis}

Mortality of adult $T$. chilonis was noted in all samples treated with insecticide and no mortality was observed in control, one day after treatment. Mortalities were significantly different across the treatments $(\mathrm{F}=86.6, \mathrm{df}=3 ; 36, \mathrm{P}<0.01)$. However, mortalities of adults treated with Chlorfluazuron, Neem and Water (control) were not significantly different to each other. Profenophos $500 \mathrm{~g} / \mathrm{L}$ EC produced $74.4 \pm 7.4 \%$ mortality, one day after treatment. This suggests that spraying of Profenophos $500 \mathrm{~g} / \mathrm{L} \mathrm{EC}$ for control of cabbage caterpillars is not a good strategy in terms of conservation of egg parasitoid, T. chilonis. Studies on mortality effect of different insecticides on $T$. chilonis indicated that the effect varies with the type of insecticides and chitin bio synthesis inhibitors are relatively less toxic (Hussain et al., 2012 and Abdelgadar, 2010).

Longevity of $T$. chilonis who survived the insecticide treatments at adult stage significantly varied with different insecticide treatments $(\mathrm{F}=607.5, \mathrm{df}=3 ; 1996, \mathrm{P}<0.01)$. The lowest longevity was recorded with profenophos $500 \mathrm{~g} / \mathrm{L} \mathrm{EC}(1.3 \pm 0.02 \mathrm{~d})$ followed by chlorfluazuron $50 \mathrm{~g} / \mathrm{L} \mathrm{EC}$ $(7.8 \pm 0.49 \mathrm{~d})$ and neem $(9.19 \pm 0.23 \mathrm{~d})$. The highest longevity was recorded in control $(12.5 \pm 0.23$ d). Highly detrimental effect of profenophos on $T$. exigum has been reported (Charles et al., 2000). Based on these results, it could be suggested that neem or chlorfluazuron $50 \mathrm{~g} / \mathrm{L} \mathrm{EC}$ can be used for cabbage pest control causing minimum adverse effect on T. chilonis adults.

The parasitism level of the survived adults after exposed to different insecticides showed significantly different levels of parasitism $(\mathrm{F}=37.6, \mathrm{df}=3 ; 76, \mathrm{P}<0.01)$. Mean levels of parasitism of C. cephalonica eggs by $T$. chilonis treated with water, neem, chlorfluazuron and profenophos were $58.3 \pm 4.0,51.5 \pm 3.9,48.0 \pm 4.6$ and $8.3 \pm 1.3$ respectively.

\section{Effect of insecticides on mortality of immature stages of Trichogramma chilonis}

In exposure of different growth stages of $T$. chilonis to insecticide produced significant difference in mortality among treatments $(\mathrm{F}=1103, \mathrm{df}=3 ; 228, \mathrm{P}<0.01)$ and also among the development stages $(\mathrm{F}=42.8, \mathrm{df}=2 ; 228, \mathrm{P}<0.01)$. In addition, the interaction: stage of $T$. chilonis $x$ insecticide treatments $(\mathrm{F}=14.7 \mathrm{df}=6 ; 228, \mathrm{P}<0.01)$ was also significant. 
With respect to the insecticide treatments across all growth stages, there was a significant difference $(\mathrm{F}=647, \mathrm{df}=3 ; 236, \mathrm{P}<0.01)$ among mortalities. The highest mortality produced by profenophos $(100 \%)$, followed by neem $(22.7 \pm 2.3)$, and chlorfluazuron (17.6 \pm 2.2$)$. However, latter two mortalities were not significantly different.

There was a significantly different mortalities among treatments, when 1 day old stage ( $\mathrm{F}=288.7$, $\mathrm{df}=3 ; 76, \mathrm{P}<0.01), 5$ day old stage $(\mathrm{F}=297.5, \mathrm{df}=3 ; 76, \mathrm{P}<0.01)$, and 7 day old stage $(\mathrm{F}=696$, $\mathrm{df}=3 ; 76, \mathrm{P}<0.01$ ) of $T$. chilonis were exposed to the insecticides. However mortalities of 1 day old stage of $T$. chilonis, produced by the treatments: chlorfluazuron and neem were not significantly different. Similarly, mortalities of 7 day old stage of $T$. chilonis, produced by the treatments: chlorfluazuron, profenophos and neem were not significantly different (Table 1). Effects of different insecticides on mortality of immature stages of Trichograma species, including T. chilonis have been reported (Rahman and Aziz, 2012, Carvalho et al., 2003, Alagar et al., 2007; Ravivarman and Veeravel, 2010). Synthetic organophosphate insecticides are generally detrimental on immature stages while chitin bio synthesis inhibitor type insecticides are less harmful (Abdelgader, 2010). Further, Bt formulations (Ksentini et al., 2010) and botanicals (Basappa, 2007) found less harmful for immature stages of Trichogramma species. As per the findings of the present study, neem and chlorfluazuron $50 \mathrm{~g} / \mathrm{L} \mathrm{EC}$ are found less harmful on T. chilonis, hence could be used in cabbage pest control along with the T. chilonis. On the other hand profenophos $500 \mathrm{~g} / \mathrm{L} \mathrm{EC}$ is not suitable to use in cabbage pest control along with egg parasitoids. Profenophos completely inhibits the emergence of parasitoids from parasitized eggs (Charles et al., 2000).

The longevity of the adult parasitoids which emerged from the immature stages of $T$. chilonis, exposed to insecticide treatments was significantly varied with the stages of development $(\mathrm{F}=101.3, \mathrm{df}=2 ; 8086, \mathrm{P}<0.01)$, and also with the insecticides $(\mathrm{F}=3136, \mathrm{df}=3 ; 8086, \mathrm{P}<0.01)$. In addition, interactions between development stages and insecticides $(\mathrm{F}=1050, \mathrm{df}=6 ; 8086$, $\mathrm{P}<0.01$ ) was significant. There were no survivors when $T$. chilonis immature stages were exposed to profenophos $500 \mathrm{~g} / \mathrm{L}$ EC which agrees with Charles et al. (2000). However, neem and chlorfluazuron significantly reduce the longevity of survived adult of $T$. chilonis compared with the untreated control (Table 1). Chlorfluazuron appears to have an effect on longevity irrespective to the growth stages of $T$. chilonis but the effect of neem on adult longevity varied with the growth stages of $T$. chilonis (Table 1).

When one day old parasitized eggs (Egg stage of T. chilonis) were treated with insecticides, there was a significant difference of the level of parasitization among adults who emerged from the insecticide treated eggs $(\mathrm{F}=284, \mathrm{df}=3 ; 76, \mathrm{P}<0.01)$. However, levels of parasitization of adults treated with chlorfluazuron and neem were only nearly significantly $(\mathrm{P}=0.013)$. Similarly, when five day old parasitized eggs (early pupae of $T$. chilonis) were treated with insecticides, there was a significant difference in levels of parasitization among adults who survived upon insecticide treatments $(\mathrm{F}=152, \mathrm{df}=3 ; 76, \mathrm{P}<0.01)$. However, the levels of parasitization of adults treated with chlorfluazuron and neem were not significantly different. Further, when seven day old parasitized eggs (pupa of $T$. chilonis) were treated with insecticides, there was a significant difference of level of parasitization among adults who survived upon insecticide treatments $(\mathrm{F}=300, \mathrm{df}=3 ; 76, \mathrm{P}<0.01)$. However, levels of parasitization of adults treated with chlorfluazuron and control were only nearly significantly different $(\mathrm{P}=0.037)$ (Table 1$)$. Capacity of Trichogramma adults for parasitization varies with the effect of different insecticides (El-sebai and El-tawai, 2011). 
Table 1. Effect of different insecticides on development stages of T. chilonis in terms of mortality, and parasitism and longevity of survived adults

\begin{tabular}{lccc}
\hline Treatment & Mortality (\%) & Parasitism (\%) & Longevity (d) \\
\hline Control & & & \\
1 day old immature $T$. chilonis (egg) & $5.7 \pm 1.6$ & $83.2 \pm 2.1$ & $12.3 \pm 0.2$ \\
5 day old immature $T$. chilonis (larva) & $6.0 \pm 1.9$ & $72.5 \pm 3.1$ & $12.4 \pm 0.2$ \\
7 day old immature $T$. chilonis (pupa) & $6.0 \pm 1.7$ & $80.1 \pm 2.5$ & $12.4 \pm 0.2$ \\
Neem & & & \\
1 day old immature $T$. chilonis (egg) & $38.1 \pm 2.3$ & $67.1 \pm 3.0$ & $4.2 \pm 0.2$ \\
5 day old immature $T$. chilonis (larva) & $21.3 \pm 3.9$ & $59.4 \pm 3.3$ & $10.0 \pm 0.3$ \\
7 day old immature $T$. chilonis (pupa) & $8.9 \pm 2.6$ & $58.5 \pm 2.5$ & $8.6 \pm 0.2$ \\
Chlorfluazuron 50g/L EC & & & \\
1 day old immature $T$. chilonis (egg) & $33.9 \pm 3.7$ & $59.4 \pm 2.3$ & $6.2 \pm 0.1$ \\
5 day old immature $T$. chilonis (larva) & $14.1 \pm 2.6$ & $60.9 \pm 2.7$ & $6.5 \pm 0.1$ \\
7 day old immature $T$. chilonis (pupa) & $4.8 \pm 1.7$ & $73.7 \pm 2.4$ & $6.1 \pm 0.1$ \\
Profenophos 500 g/L EC & & & \\
1 day old immature $T$. chilonis (egg) & $100 \pm 0$ & $0 \pm 0$ & $0 \pm 0$ \\
5 day old immature $T$. chilonis (larva) & $100 \pm 0$ & $0 \pm 0$ & $0 \pm 0$ \\
7 day old immature $T$. chilonis (pupa) & $100 \pm 0$ & $0 \pm 0$ & $0 \pm 0$ \\
\hline
\end{tabular}

Parasitizing capacity of adults emerged from the different development stages of $T$. chilonis exposed to different insecticides significantly varied with the exposed development stages $(\mathrm{F}=5.4, \mathrm{df}=2 ; 228, \mathrm{P}<0.01)$ and also with the insecticide treatments $(\mathrm{F}=682, \mathrm{df}=3 ; 228, \mathrm{P}<0.01)$.

Effect of insecticide residues on substrate on acceptance of host eggs by Trichogramma chilonis

Acceptance of $C$. cephalonica eggs on substrates that had been treated with insecticides was evaluated through assessing the levels of parasitism. Acceptance of $C$. cephalonica eggs by $T$. chilonis significantly varied with insecticide treatment $(\mathrm{F}=297.5 \mathrm{df}=3 ; 304, \mathrm{P}<0.01)$ and the time duration after insecticide treatment $(\mathrm{F}=313.4 \mathrm{df}=3 ; 304, \mathrm{P}<0.01)$. Further, the interaction between insecticide treatment and time duration after insecticide treatment $(\mathrm{F}=35.9 \mathrm{df}=9 ; 304$, $\mathrm{P}<0.01)$ was significant.

There was a significant difference of level of acceptance $(\mathrm{F}=59.9$, $\mathrm{df}=3 ; 316, \mathrm{P}<0.01)$ among insecticide treatments as assessed by level of parasitism across all time durations $(0,5,15$ and $25 \mathrm{~d})$. However, acceptances of substrates treated with neem and chlorfluazuron was not significantly different. A similar trends: significant differences among insecticide treatments and no significant difference between neem and chlorfluazuron was found when assessments were done $0 \mathrm{~d}(\mathrm{~F}=267, \mathrm{df}=3 ; 76, \mathrm{P}<0.01)$ and $5 \mathrm{~d}(\mathrm{~F}=92.3, \mathrm{df}=3 ; 76, \mathrm{P}<0.01)$ durations after treating the substrates. However it was significantly different for 15 days $(\mathrm{F}=43.5, \mathrm{df}=3 ; 76, \mathrm{P}<0.01)$ and 25 days $(\mathrm{F}=21.4, \mathrm{df}=3 ; 76, \mathrm{P}<0.01)$ after treating the substrates (Figure 2$)$. 


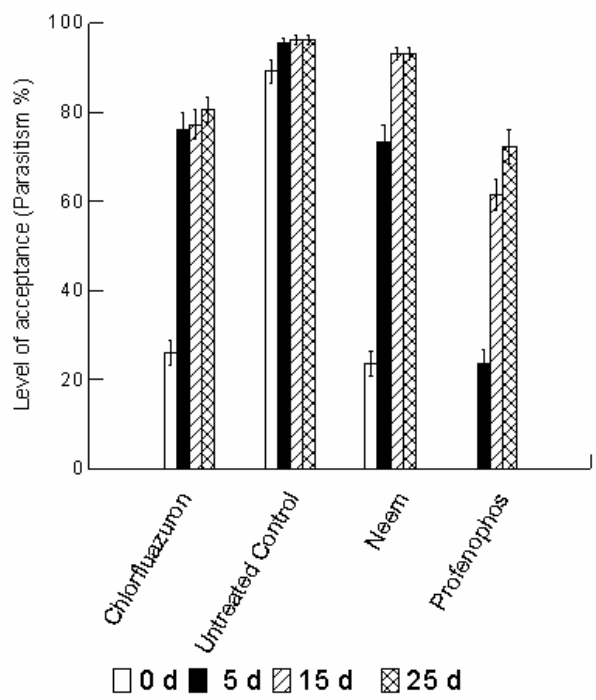

Fig. 2. Acceptance of host eggs on treated substrate by T. chilonis after different time durations. Level of acceptance was determined by assessing level of parasitism

Overall results indicated that it takes about 10-15 days to become the crucifer field safer for the adult parasitoids upon the application of insecticides and the duration depends on the type of insecticides.

Host searching behaviour of Trichogramma chilonis: Influence of host, host density, and the substrate on host finding behaviour of Trichogramma chilonis

\section{Effect of substrate for host finding behaviour}

There was a significant difference among the time durations $(\mathrm{F}=8.043, \mathrm{df}=2 ; 228, \mathrm{P}<0.05)$ taken by $T$. chilonis to locate the Corcyra eggs, which is the surrogate host used for all the experiments when eggs were presented on different substrates. Mean time duration was $328.25 \pm 18$ seconds when eggs were on a filter paper, followed by croton $(384.51 \pm 18)$ and cabbage $(430.57 \pm 18)$. It is believed that parasitoids use the cues emitting from plants to locate the host habitat as well as host. This may be applicable to T. chilonis as well. Natural host of T. chilonis, which is $T$. ni, lays eggs on cabbage; hence, it was expected that $T$. chilonis is would find hosts quickly when eggs were on cabbage leaf. However, in this experiment shortest time duration to locate the eggs was observed on filter paper which was the neutral substrate indicating that $T$. chilonisis is well capable of locating the host even without the cues from substrate. Cues from host (eggs) appeared to be sufficient for T. chilonis to locate the host (eggs). This could be benefitted for the survival of this parasitoid during the off season of cabbage cultivation. It was also found that, $T$. chilonis could be reared on C. cephalonica eggs without getting cabbage plants involved.

\section{Effect of host density on host finding behaviour}

There was a significant difference among time durations taken to find hosts when eggs were provided at different densities $(\mathrm{F}=7.5, \mathrm{df}=3 ; 228, \mathrm{P}<0.05)$. Time duration taken when 7 eggs were presented together was 170.55 seconds which was significantly different from the densities: 
one and three eggs per substrate; however, it was not significantly different from the density of five eggs per substrate (Figure 3(A)).

It is believed that $T$. chilonisis is capable of detecting volatile compounds emitted from its hosts (host related chemical cues). The emission of oviposition-induced volatiles, or volatiles emitted from host chorion allow parasitoids to locate the host (Colazza et al., 2010). With the increase of the number of eggs, time duration taken by $T$. chilonis to find the host was decreased. With the number of eggs increase, the concentration of those volatile compounds also could be increased. This facilitates the parasitoid to locate the hosts (Schmidt, 1994). Under field condition, T. ni lays eggs individually and sometimes several eggs in the same spot. Those eggs are easily parasitized by $T$. chilonis. Since $T$. chilonis is attracted to host related chemical cues provided by host eggs and poorly responding to the chemicals from host plants, T. chilonis could use in biological control of cabbage pests in different crucifer crops, because cabbage pests can survive on other crucifer crops like mustard. In addition, it can be suggested that $T$. chilonis could be reared without getting the host plants involved.

There was a significant difference between the time taken to find hosts when $C$. cephalonica and T. $n i(\mathrm{~F}=46.22, \mathrm{df}=1 ; 152, \mathrm{P}<0.05)$ were used as hosts. Time durations, $299.6 \pm 3.9$ seconds and $625.6 \pm 3.9$ seconds were taken when hosts were Corcyra and T. ni respectively (Figure 3(B)). However it was expected that $T$. chilonis take lesser time to locate natural host, $T$. $n i$, than the alternative host. The results showed that less time was taken to locate C. cephalonica.

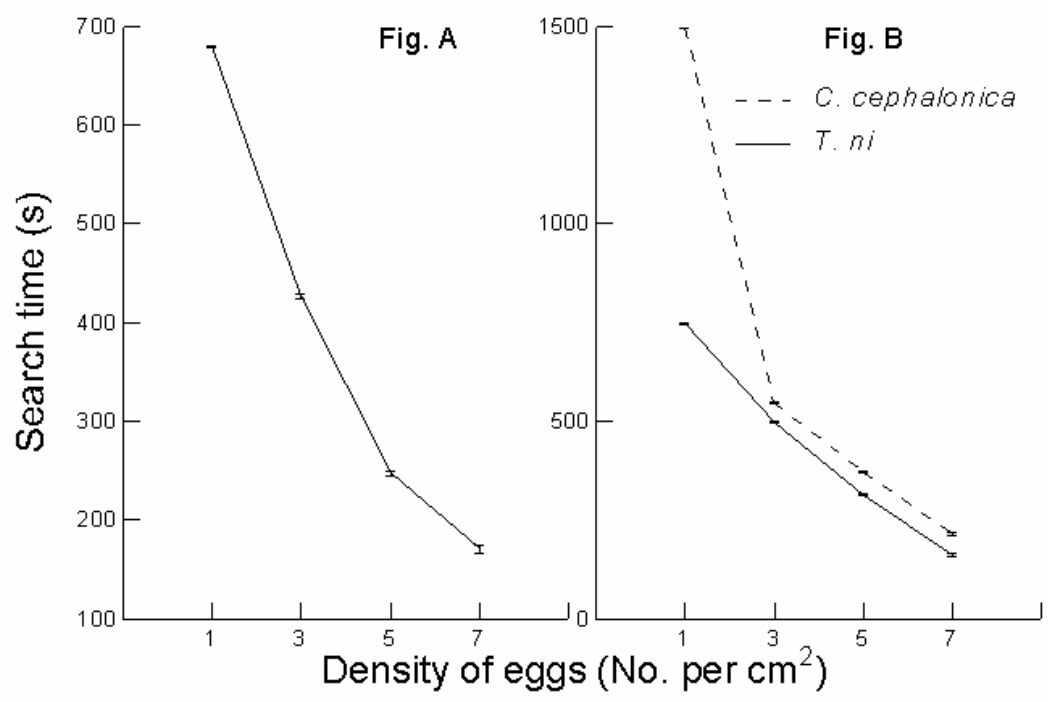

Fig. 3. (A). Time taken by $T$, chilonis to search Corcyra cephalonica eggs, when eggs were presented at different densities on filter paper within a clear plastic vial (2.5 $\mathrm{cm}$ diameter and $6.7 \mathrm{~cm}$ height) under laboratory conditions

\section{(B). Time taken by T. chilonis to search Corcyra cephalonica and Trichoplusia ni eggs when different numbers of eggs were placed on the cabbage leaf}

These results agree with the Puneeth and Vijayan (2013), who showed that there is no special attraction of T. chilonis for T. ni. After field release, T. chilonis will be able to parasitize other caterpillars as well as $T$. $n i$, without any special attraction. This ability may ensure the survival of 
T. chilonis. However, T. chilonis may shift to another host, depending on the host availability. It has been reported that, $C$. cephalonica is more successful than Spodoptera litura, in mass-rearing of Trichogramma sp. Emergence and viability rate of Trichogramma was much higher, who reared on $C$. cephalonica than Spodoptera litura (Puneeth and Vijayan, 2013). The relationship between host density (as stated above) and time duration to find host seems valid even for $T$. $n i$. Time duration taken to locate host decreased when host density increases.

\section{Searching behaviour of Trichogramma chilonis within cabbage plant}

Ability of $T$. chilonis to locate hosts within cabbage plant was examined in this experiment. There was no significant difference among host search within the layers (upper-U, middle-M and lower-L) of the plant. Out of 300 points of the plant, T. chilonis was able to locate hosts on 126 points. From that, 35\% were on upper layer, 30\% were on lower layer and 38\% on middle layer. This suggests that $T$. chilonis is capable of finding hosts at any layer of the plant. The results of this experiment agree with Suverkropp et al. (2010). There is no significant difference between the host search of upper (U) and lower (L) side of the leaf. 50.79\% of host search was on upper side and it was 49.21 on lower side. It suggests that $T$. chilonis can search both sides of the leaves to find the host. This behavioural character is highly influential on efficacy of parasitoids in the field.

There was no significant difference among host search on each point of leaf. $24.60 \%$ of total host search was observed at leaf petiole and it was $16.67 \%$ on leaf tip. This result showed that $T$. chilonis can equally search the leaf to find its host.

Overall results of these experiments suggest that, $T$. chilonis search the hosts more or less randomly, which agrees with Suverkropp et al. (2009). This is an important beneficial behaviour of $T$. chilonis with respect to efficient biocontrol agent. According to Suverkropp et al. (2010), $87 \%$ of Trichogramma visit both sides of the maize leaf under $25{ }^{\circ} \mathrm{C}$. In this experiment also, there was no significant difference between the hosts search on leaf sides: upper and lower surfaces. According to, Suverkropp et al. (2010), most searched area of T. chilonis in maize plants was close to stem but in the present experiment, no such area of the leaf preferred by $T$. chilonis

\section{Time taken for maximum parasitism with adlibitum access to host eggs}

Egg laying pattern has a significant relationship. The relationship of probability of parasitization of eggs with time was significantly explained by $\mathrm{Y} /(1-\mathrm{Y})=\exp \left(\mathrm{X}^{*} 1.090-1.563\right) \mathrm{n}=15$ $\mathrm{P}<0.001$. More than $80 \%$ of egg load of female parasitoid was laid within first three hours when hosts were at ample supply. T. chilonis lays the entire egg load within four hours when host eggs are supplied without any limitations. This feature is considered as an advantage in augmentation as the parasitoid would explore its host within four hours after release. Host egg age has a significant effect on parasitism percentage by $T$. chilonis. Parasitism percentage reported to be decreased with the age of the host egg (Miura and Kobayashi, 1998, Sultan et al., 2013). Within five hours, entire egg load of parasitoid was deposited. This proves that $T$. chilonis can be used to control a higher pest infestation within a short time period (Figure 4). This also can be considered as a positive character in mass rearing. 


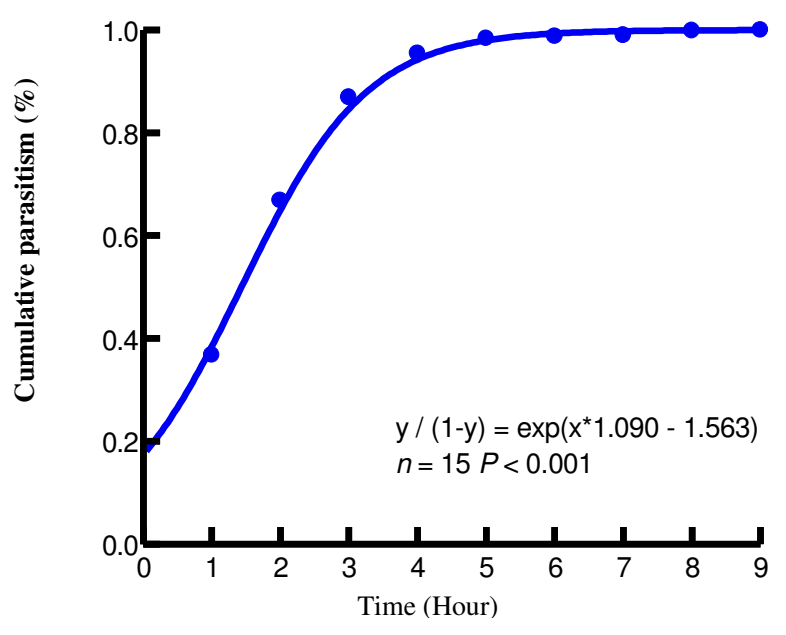

Fig. 4. Cumulative parasitism percentages of eggs by Trichogramma chilonis with time when ample number of Corcyra cephalonica eggs were provided within clear plastic vial $(2.5 \mathrm{~cm}$ diameter and $6.7 \mathrm{~cm}$ height) under laboratory conditions

\section{Relationship between parasitism level and host density}

There was a significant difference of percentage parasitism among the egg densities ranged from 15 to 100 eggs per arena $(\mathrm{F}=24.55, \mathrm{df}=4 ; 70, \mathrm{P}<0.05)$. There was no significant difference in parasitism $(74.5 \%)$ between egg densities; between 15 and 25 eggs per arena. Maximum parasitism percentage was observed under density of 50 eggs (78\%). After 50 eggs, parasitism percentage decreased with the increase of egg densities: 75 (48.9 \pm 5.7$)$ and $100(33.1 \pm 1.9)$. This shows that there is a significant difference of percentage parasitism with the egg density with apparent negative density dependant relationship.

\section{CONCLUSIONS}

The response of Trichogramma chilonis to different insecticides varied. Profenophos, an organophosphate insecticide, was highly detrimental for adult $T$. chilonis, while chlorfluazuron and neem can be used without much interference to the survival, longevity and parasitism. Survived adults upon the exposure to insecticides at immature stage performed differently in terms of parasitism. T. chilonis is capable of searching host eggs, irrespective to the substrates. It did not prefer to Trichoplusia ni, which was the natural host. Corcyra cephalonica can be suggested as a good alternative host for rearing $T$. chilonis. $T$. chilonis is capable of searching entire plant for host eggs including all layers of plant and both surfaces of leafs. Having considered all these characters, it can be suggested that $T$. chilonis is a potential candidate to promote as a bio control agent through augmentation and release for managing $T$. ni population. 


\section{ACKNOWLDEGEMENT}

National Science Foundation (NSF), Colombo is acknowledged for the financial assistance (Grant no. RG/2011/AG/05).

\section{REFERENCES}

Abdelgadar, H. (2010). Novel methods to combat insect pests in Sudan. Aspects of Applied Biology, 96, 91 - 96.

Alagar, M., Sivasubramanian, P., Saravanan, P.A. and Amutha, M. (2007). Safety of botanicals and insecticides to Chrysoperla carnea Stephens and Trichogramma chilonis Ishii. J. Plant. Prot. Environ. 4(2), 7 - 14.

Basappa, H. (2007). Toxicity of biopesticides and synthetic insecticides to egg parasitoid, Trichogramma chilonis Ishii and coccinellid predator, Cheilomenes sexmaculata. (Fabricius). J. Biol. Control, 21(1), 31 - 96.

Bassil, K.L., Vakil, C. Sanborn, M. Cole, D.C. Kaur, J.S. and Kerr, K.J. (2007). Cancer health effects of pesticides: systematic review. Can. Farm Physician 53(10), 1704 - 11.

Carvalho, G.A., Reis, P.R., Rocha, L.C.D., Moraes, J.C., Fuini, L.C. and Ecike, C.C. (2003). Side-effects of insecticides used in tomato fields Trichogramma pretiosum Riley (Hymenoptera: Trichogrammatidae), Acta Scientiarum, 25, 275 - 279.

Charles, P.C.S., David, B.O. and John, W.V.D. (2000). Effect of Insecticides on Trichogramma exiguum (Trichogrammatidae: Hymenoptera) pre-imaginal development and adult survival. J. Econ. Entomol., 93(3), 577 - 583.

Colazza, S., Peri, E., Salerno., G. and Conti, E. (2010). Host searching by egg parasitoids: Exploitation of host chemical cues. pp. 97-137. In: Consoli, F.L., Parra, J.R.P. and Zucchi, R.A. (Eds.) Egg parasitoids in agro-ecosystems with emphasis on Trichogramma. Springer Science Business Media. Piracicaba, Brazil.

DOA (2010). Pesticide recommendations, Department of Agriculture press, Peradeniya.

DOA (2013). Pocket book of agricultural statistics, Vol. X, pp.31.

El-sebai. O.A. and El-tawai, M.F. (2011). Effect of conventional insecticides on the egg parasitoid, Trichogramma evanescens (West.) (Hymenoptera: Trichogrammatidae). Egypt. J. Biol. Pest. Control, 21(1), 39 - 44.

Gilden, R.C., Huffling, K., and Sattler, B. (2010). Pesticides and health risks. J. Obstet. Gynecol Neonatal Nurs., 39(1), $103-110$.

Hemachandra, K.S., Polazek, A. and Singhamuni, S.A. (2013). Egg parasitoids of Trichoplusia ni: Trichogramma achaeae Nagaraja and Nagarkatti 1969, and Trichogramma chilonis Ishii (Hymenoptera: Trichogrammatidae) in Sri Lanka. $1^{\text {st }}$ Ruhuna International Science \& Technology Conference, University of Ruhuna, Matara, Sri Lanka, 1, 86. 
Heong, K.L., Teng, P.S. and Moody, K. (1995). Managing rice pests with less chemicals. Geo. Journal, 35(3), 337 - 349.

Hussain, D., Ali, A., Hassan, M.M., Ali, A., Saleem, M. and Nadeem, S. (2012). Evaluation of Toxicity of some new insecticides against egg parasotoid Trichogramma chilonis (Ishii) (Hymenoptera: Trichogrammitidae). Pakistan J. Zool., 44(4), 1123 - 1127.

Jurewicz, J. and Hanke, W. (2008). Parental and childhood exposure to pesticides and neurobehavioral development: Review of epidemiological studies. Int. J. Occup. Med. Environ Health, 21(2), $121-32$.

Ksentini, I., Jardak, T. and Zeghal, N. (2010). Bacillus thuringiensis, deltamethrin and spinosad side-effects on three Trichogramma species. Bull. Insectology, 63(1), 31 - 37.

Miura, K. and Kobayashi, M. (1998). Effect of host egg age on the parasitism by Trichogramma chilonis Ishii an egg parasitoid of the diamondback moth. Appl. Entomol. Zool., 33(2), 219 222.

Ooi, P.A.C. and Shepard, B.M. (1994). Predators and parasitoids of rice insect pests pp 585-612. In: Heinrichs, E.A. (Ed.), Biology and management of rice insects. Wiley Eastern Limited, New Delhi.

Puneeth, P. and Vijayan, V.A. (2013). Biocontrol efficiency and viability of Trichogramma chilonis Ishii on Corcyra cephalonica and Spodopteralitura under laboratory conditions. Int. J. Biol. Sci., 3(1), 76 - 79.

Rahman, A. and Aziz, A. (2012). Effect of three insecticides on development of Trichogramma cacoeciae Marchal (Hymenoptera: Trichogrammatidae) under laboratory conditions. Egypt. J. Biol. Pest. Control, 22(2), 109 - 114.

Ravivarman, B. and Veeravel, R. (2010). Preliminary studies on the effect on insecticides on the emergence of Trichogramma chilonis (Ishida). Insect Environ., 15(4): 152.

Sattar, S., Farman,U., Saljoqi, A.U.R., Arif, M., Sattar, H. and Qazi, J.I. (2011). Toxicity of some new insecticides against Trichogramma chilonis (Hymenoptera: Trichogrammatidae) under laboratory and extended laboratory conditions. Pakistan J. Zool., 43(6), 1117 - 1125.

Sheiner, E.K., Sheiner, E., Hammel, R.D., Potashnik, G. and Carel, R. (2003). Effect of occupational exposures on male fertility: literature review. Ind. Health, 41(2), 55 - 62

Schmdt, J.M. (1994). Host recognition and acceptance by Trichogramma. pp. 165-193. In: Wajnberg, E. and Hasan, S.A. (Eds.). Biological control with Egg Parasitoids. International institute of Biological Control, Berkshire, UK.

Sultan, R., Khan, J., Haq, E.U., Mehemood, T., Khattak, R.Z. and Akhtar, N. (2013). Biological parameters of Trichogramma chilonis Ishii (Trichogrammatidae: Hymenoptera) feeding on Sitotroga cerealella eggs at three constant temperatures. Pakistan J. Agric. Res., 26(1), 65 - 70.

Suverkropp B.P., Bigler, F. and Vanlenteren, J.C. (2010). Movement and host finding of Trichogramma brassicae on maize plants. Bull. Insectology, 63(1), 115 - 127. 
Singhamuni et al.

Suverkropp, B.P. Bigler, F. and Vanlenteren, J.C. (2009). Dispersal behaviour of Trichogramma brassicae in maize fields. Bull. Insectology, 62(1), $113-120$.

TNAU AGRITECH PORTAL, Bio control, mass production of parasitoids. Cyber extension: [on line]. [Accessed on 25.05.2012]. Available at

http://agritech.tnau.ac.in/crop_protection/crop_prot_bio_mass_parasitoids.html. 